http://jmscr.igmpublication.org/home/ ISSN (e)-2347-176x ISSN (p) 2455-0450

crossref DOI: https://dx.doi.org/10.18535/jmscr/v7i11.76

\author{
Dournal Of Medical Science And Clinical Research \\ IGM Publication \\ An official Publication of IGM Publication
}

\title{
Prospective Study of Blunt Trauma Chest
}

\author{
Authors \\ Piyush K. Sinha ${ }^{1}$, Kapil Sindhu ${ }^{2}$, Ashish K Chaudhary ${ }^{3}$, Ashutosh Bawa ${ }^{4}$, \\ Minal Panwar ${ }^{5}$ \\ ${ }^{1,3}$ Senior Resident, Dept. of Surgery, MMIMSR Mullana Ambala 133207 \\ ${ }^{2}$ Assistant Professor, Dept. of Surgery, MMIMSR, Mullana Ambala 133207 \\ ${ }^{4}$ Junior Resident, Dept. of Surgery, MMIMSR Mullana Ambala 133207 \\ ${ }^{5}$ Assistant Professor, Dept. of Pediatrics, MMIMSR, Mullana Ambala 133207
}

\begin{abstract}
Introduction: Trauma is a major cause of morbidity and mortality in both developed and developing countries. Globally $10 \%$ of all trauma admissions results from chest injury and $25 \%$ of trauma related deaths are attributed to chest injuries. Chest trauma may present as isolated injury or as a part of polytrauma. The incidence of chest injuries are on a rise, with motor vehicle accidents (MVA) playing the most important role. Chest trauma can be broadly divided into two categories: blunt chest injuries \& penetrating chest injuries. Blunt trauma chest is often associated with injuries to other organs, especially the abdominal solid organs as the upper part of the abdomen is overlapped by the thoracic cage. Very few studies have been conducted to analysis the magnitude and management of blunt chest trauma in Indian scenario.
\end{abstract}

Aim \& Objectives: To study the clinical profile of cases with blunt trauma chest in reference to mode of injury, hospital stay, diagnosis, severity of injury, treatment offered morbidity and mortality.

Material \& Methods: A prospective, observational, clinical study was conducted at Department of Surgery, MMIMSR, Mullana, and Ambala. Consecutive type of non-probability sampling was used for the selection of study subjects during study duration. A total of 50 consecutive cases fulfilling the eligibility criteria were taken for study after informed consent. Data was collected from these patients admitted in surgical wards and ICU. All the patients admitted with provisional diagnosis of blunt trauma chest were admitted in surgical ward/ ICU. Data was analyzed using statistical software SPSS ver. 21.

Results: Mean age of the subjects with blunt chest trauma was 33.32 years with almost two third of cases belonging to 18-40 years of age (64\%). Male predominance was seen among study cases with $74 \%$ males to $26 \%$ females. Mode of injury was road traffic accident in 54\% cases while it was fall in $34 \%$ cases. Decelerated injury was observed in $76 \%$ cases while polytrauma was seen in $36 \%$ cases. Most common presenting symptom was chest pain (92\%) followed by dyspnoea (82\%), abdominal pain (24\%), nausea/vomiting (22\%). Surgical/ Subcutaneous Emphysema was observed in 32\% cases. Hemothorax, pneumothorax and Pneumo-hemothorax was seen in 52\%, $26 \%$ and $12 \%$ cases respectively. As per injury severity score, low to medium severity injury was observed in $66 \%$ and $22 \%$ cases respectively. Severe injury was seen in $12 \%$ cases. As per injury severity score, low to medium severity injury was observed in $66 \%$ and $22 \%$ cases respectively. Severe injury was seen in $12 \%$ cases. Conservative management was sufficient in $36 \%$ cases while remaining cases required surgical intervention. Tube thoracotomy was required in $62 \%$ while mechanical ventilation was seen in $36 \%$ cases. Laparotomy was required in $20 \%$ cases. Pneumonia developed in 10\% cases while pyothorax and septicaemia was seen in $4 \%$ and $8 \%$ cases respectively. Acute renal failure and Multi-organ dysfunction was seen in 1 case each. Increased injury severity score was associated with poly-trauma patients $(p<0.01)$. Mean hospital and ICU stay was more in polytrauma cases as compared to isolated chest trauma cases $(p<0.05)$. Incidence of Mortality was $4 \%$ in present study.

Conclusion: Blunt trauma chest is more common among the young males. Increased outdoor activities and vehicular 
accidents are responsible for increased blunt trauma chest. The commonest injury was rib fracture followed by hemothorax and pneumothorax. The most common associated injury was clavicle fracture while most common abdominal solid organ injury was that of liver. About two third cases required tube thoracotomy while $36 \%$ of cases were managed conservatively. Pneumonia was the most common complication encountered followed by septicaemia and pyothorax. The overall mortality rate in this series was $4 \%$. The determinant of severe injury was polytrauma which leads to increased hospital/ ICU stay.

\section{Introduction}

Trauma represents a major epidemic of noncommunicable disease in present century. They are no longer considered accidental but are part of the price we pay for the technological progress ${ }^{[1]}$. Trauma is a major cause of morbidity and mortality in both developed and developing countries. The usual causes are road traffic accidents (RTAs), fall from height, occupational injuries, and assault. According to the World Health Organization report on road safety, RTAs would be the fifth leading cause of death worldwide by the year $2030^{[2]}$.

Globally $10 \%$ of all trauma admissions results from chest injury and $25 \%$ of trauma related deaths are attributed to chest injuries ${ }^{[4,5]}$. It is a major problem for India, also due to a very high incidence of vehicular accidents $(6 \%$ of global vehicular accidents), other accidental injuries, crime and violence. In India approximately 16000 deaths per year alone are a result of chest trauma [6]

According to the National Trauma Database $(\mathrm{NTDB})^{[12]}$, chest injuries are present in $13.8 \%$ of all blunt trauma patients. The overall mortality rate of chest trauma is $8.4 \%$. The mortality rate of blunt thoracic trauma ranges from 9.5\%-47.5\%, depending upon the severity of injury sustained. The most common cause is motor vehicular accident (MVA), followed by fall. MVAs account for $70-80 \%$ of such injuries.

Blunt thoracic trauma is often associated with injuries to other organs, especially the abdominal solid organs as the upper part of the abdomen is overlapped by the thoracic cage. Optimal care of severely injured patients requires a coordinated approach from the point of injury, through a hospital facility organised to cope with the demands of looking after multisystem problems, to a rehabilitation structure that can return the patient to his or her maximum potential level of function within society. Although sophisticated prehospital and trauma centre systems have been shown to reduce the number of preventable deaths after trauma, maximum impact in reducing the burden of trauma must come from injury prevention strategies ${ }^{[13]}$.

This study takes into account blunt trauma chest cases being admitted to our hospital and different modalities of treatment being offered to them.

Very few studies have been conducted to analyse the magnitude and management of Blunt trauma chest in Indian scenario. This study is carried out to determine the epidemiology of the aetiology of chest trauma along with analysing the management scheme and outcome of chest injuries in a tertiary care set up in a rural area.

\section{Methodology}

Study Setting: Department of Surgery, MMIMSR, Mullana, Ambala

Study Population: Cases of Blunt Trauma Chest coming to our hospital.

Study Design: A Prospective, observational, Clinical study

Sample Size: Consecutive type of non-probability sampling was used for the selection of study subjects during study duration. A total of 50 consecutive cases fulfilling the eligibility criteria were taken for study after informed consent.

Study Duration: Oct 2016 - April 2018

\section{Inclusion Criteria}

All the adult patients of more than 18 years of age presenting with Blunt Trauma Chest admitted in Emergency or OPD.

\section{Exclusion Criteria}

Patient with Head Injury would be excluded from this study. 


\section{JMSCR Vol||07||Issue||11||Page 438-448||November}

\section{Data Collection Procedure}

Data was collected from these patients admitted in surgical wards and ICU. All the patients admitted with provisional diagnosis of blunt trauma chest were admitted in surgical ward/ ICU.

Following investigations were done in all cases:

1. Routine Hemogram.

2. Bleeding Time, Clotting Time, Blood Group.

3. Chest X-Ray PA view, USG Abdomen, USG Thorax.

4. CT Chest and Abdomen wherever required.

A special note was made of patients with Rib fracture, Hemothorax, Surgical Emphysema and so on. Injuries of Clavicular, Sternal and Scapular Fracture were also noted down. Severe injuries to tracheobronchial tree, lungs and heart were noted down.

Management in the form of conservative, tube thoracostomy, incision for surgical emphysema, thoracotomy were studied and recorded in the proforma. Number of blood transfusion required, morbidity and mortality was noted down for every patient.

\section{Results}

Table 1 Distribution of study subjects as per mode of transport of patient to hospital

\begin{tabular}{|l|c|c|}
\hline $\begin{array}{l}\text { Mode of Transport of } \\
\text { Patient to Hospital }\end{array}$ & N & $\%$ \\
\hline Ambulance & 17 & $34.0 \%$ \\
\hline Police & 6 & $12.0 \%$ \\
\hline Personal & 21 & $42.0 \%$ \\
\hline Self & 3 & $6.0 \%$ \\
\hline Unknown & 3 & $6.0 \%$ \\
\hline Total & 50 & $100 \%$ \\
\hline
\end{tabular}

Most of the cases reached hospital either by ambulance $(34 \%)$ or personal conveyance $(42 \%)$.

Table 2 Distribution of study subjects as per duration of Injury before admission (hrs)

\begin{tabular}{|l|c|c|}
\hline $\begin{array}{l}\text { Duration of Injury before } \\
\text { admission(hrs) }\end{array}$ & $\mathbf{N}$ & \% \\
\hline $\mathbf{0}$ to 2 & 12 & $24.0 \%$ \\
\hline $\mathbf{2}$ to 6 & 13 & $26.0 \%$ \\
\hline $\mathbf{6}$ to 12 & 6 & $12.0 \%$ \\
\hline $\mathbf{1 2}$ to 24 & 4 & $8.0 \%$ \\
\hline $\mathbf{2 4}$ to 48 & 6 & $12.0 \%$ \\
\hline $\mathbf{4 8}$ to 72 & 8 & $16.0 \%$ \\
\hline$>72$ & 1 & $2.0 \%$ \\
\hline Total & 50 & $100 \%$ \\
\hline
\end{tabular}

In half of the cases, duration of injury was either less than 2 hours $(24 \%)$ or between 2 to 6 hours $(26 \%)$.

Table 3 Distribution of study subjects as per pattern of trauma

\begin{tabular}{|l|c|c|c|}
\hline \multicolumn{2}{|l|}{ Pattern of Trauma } & N & $\%$ \\
\hline \multirow{2}{*}{ Pre-hospital Care offered } & 34 & $68.0 \%$ \\
\hline \multirow{2}{*}{$\begin{array}{l}\text { Arrived } \\
\text { From }\end{array}$} & Referral & 15 & $30.0 \%$ \\
\cline { 2 - 4 } & Accident site & 20 & $40.0 \%$ \\
\cline { 2 - 4 } & Delayed & 15 & $30.0 \%$ \\
\hline \multirow{3}{*}{$\begin{array}{l}\text { Mode of } \\
\text { Injury }\end{array}$} & Assault & 2 & $4.0 \%$ \\
\cline { 2 - 4 } & Fall & 17 & $34.0 \%$ \\
\cline { 2 - 4 } & Industrial & 4 & $8.0 \%$ \\
\hline \multirow{2}{*}{ Pattern } & RTA & 27 & $54.0 \%$ \\
\hline \multirow{2}{*}{\begin{tabular}{l} 
Type Injury \\
\cline { 2 - 4 }
\end{tabular}} & $\begin{array}{c}\text { Decelerated } \\
\text { Trauma Only }\end{array}$ & 12 & $24.0 \%$ \\
\cline { 2 - 4 } & Poly-trauma & 38 & $76.0 \%$ \\
\hline
\end{tabular}

Pre-hospital care was offered in $68 \%$ cases while direct admission from injury site was seen in $40 \%$ cases. Mode of injury was road traffic accident in $54 \%$ cases while it was fall in $34 \%$ cases. Decelerated injury was observed in $76 \%$ cases while polytrauma was seen in $36 \%$ cases.

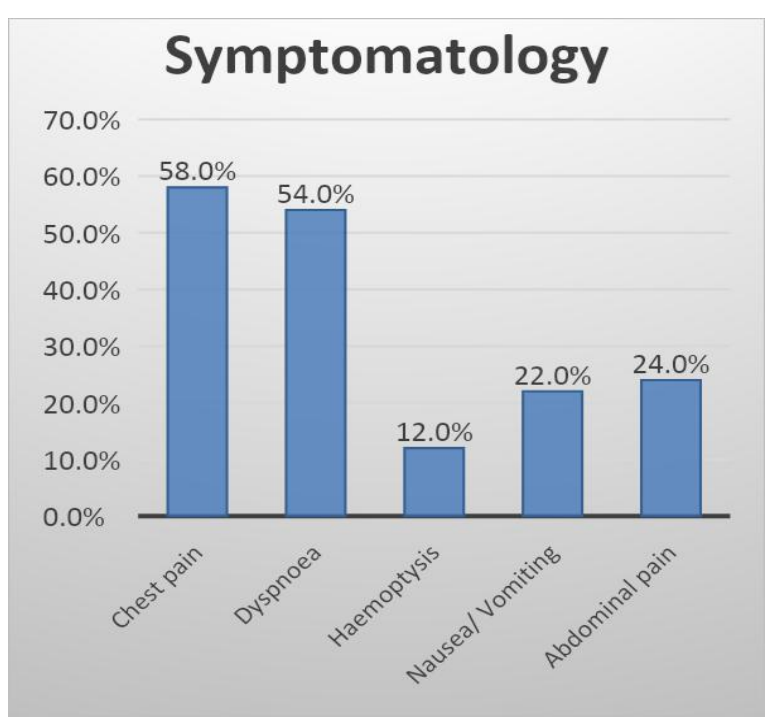

Figure 1 Distribution of study subjects as per Symptomatology

Most common presenting symptom was chest pain (58\%) followed by dyspnoea (54\%), abdominal pain (24\%), nausea/vomiting (22\%) and hemoptysis (12\%). 


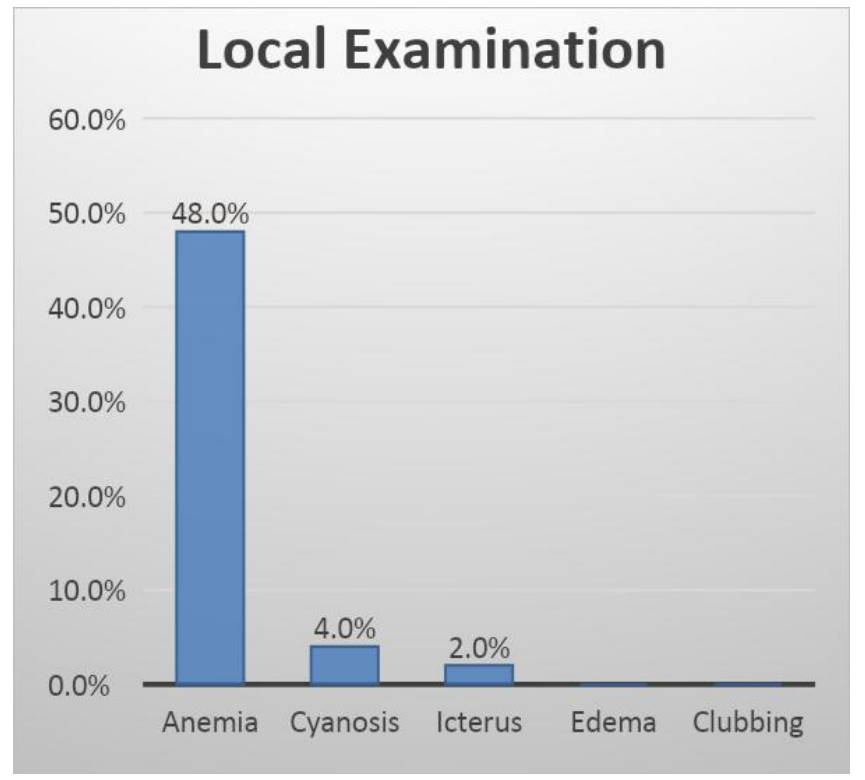

Figure 2 Distribution of study subjects as per Local examination findings

On local examination, anaemia and cyanosis was seen in $48 \%$ and $4 \%$ cases respectively.

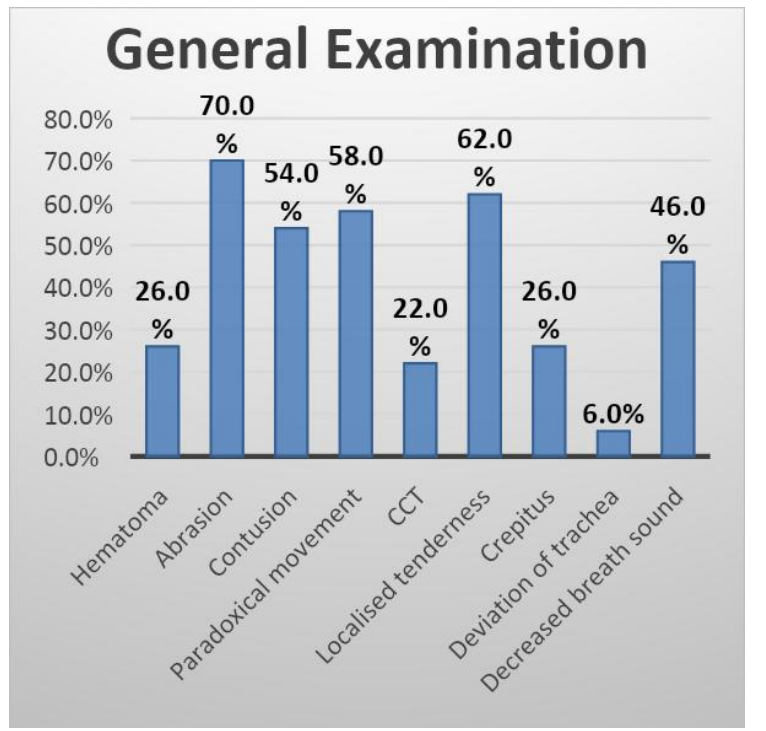

Figure 3 Distribution of study subjects as per General Examination findings

On general examination, abrasions, contusions and hematoma was seen in $70 \%, 54 \%$ and $26 \%$ cases respectively. Paradoxical chest movements and CCT was seen in $58 \%$ and $22 \%$ cases. Localised tenderness was reported in $62 \%$ cases while crepitus, deviation of trachea and decreased breath sounds were observed in $26 \%, 6 \%$ and $46 \%$ cases respectively.

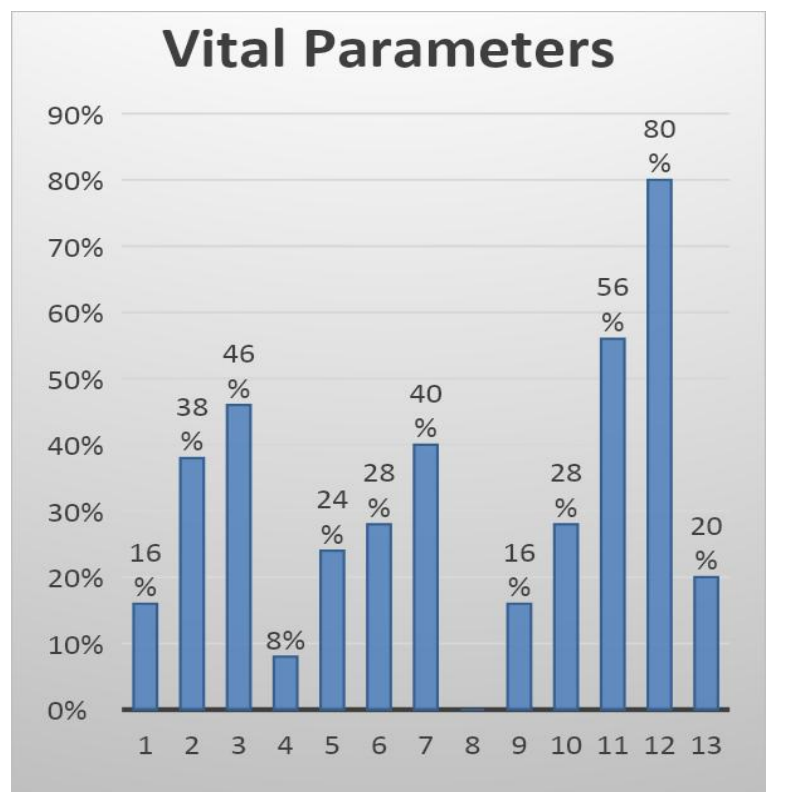

Figure 4 Distribution of study subjects as per findings of vital parameters

Bradycardia and decreased blood pressure was seen in $16 \%$ and $8 \%$ cases respectively.

Table 4 Distribution of study subjects as per Chest $\mathrm{X}$-ray findings

\begin{tabular}{|l|c|c|}
\hline Chest X-Ray & N & \% \\
\hline Rib Fractures & 29 & $58.0 \%$ \\
\hline White opacification & 9 & $18.0 \%$ \\
\hline Hemothorax & 26 & $52.0 \%$ \\
\hline Pneumo-thorax & 13 & $26.0 \%$ \\
\hline Pneumo-hemothorax & 6 & $12.0 \%$ \\
\hline Clavicle Fracture & 8 & $16.0 \%$ \\
\hline Scapula Fracture & 3 & $6.0 \%$ \\
\hline
\end{tabular}

Associated rib fractures were seen in $58 \%$ cases while white opacification s/o lung contusion and scapula-clavicular fracture was seen in $18 \%$ and $22 \%$ cases respectively. Hemothorax, pneumothorax and pneumo-hemothorax was seen in $52 \%, 26 \%$ and $12 \%$ cases respectively.

Table 5 Distribution of study subjects as per USG Thorax findings

\begin{tabular}{|l|l|l|}
\hline USG Thorax & $\mathbf{N}$ & $\mathbf{\%}$ \\
\hline Pleural effusion & 5 & $10.0 \%$ \\
\hline Internal echoes & 2 & $4.0 \%$ \\
\hline Surgical Emphysema & 16 & $32.0 \%$ \\
\hline Diaphragmatic hernia & 0 & $0.0 \%$ \\
\hline Pericardial effusion & 0 & $0.0 \%$ \\
\hline
\end{tabular}


On Thoracic ultrasound, pleural effusion was seen in $10 \%$ cases while internal echoes and surgical emphysema was seen in $4 \%$ and $32 \%$ cases respectively.

Table 6 Distribution of study subjects as per Management strategies

\begin{tabular}{|l|c|c|}
\hline Management & $\mathbf{N}$ & $\boldsymbol{\%}$ \\
\hline Tube thoracotomy & 31 & $62.0 \%$ \\
\hline Conservative for surgical & 18 & $36.0 \%$ \\
\hline $\begin{array}{l}\text { Incision for } \\
\text { emphysema }\end{array}$ & 16 & $32.0 \%$ \\
\hline Mechanical Ventilation & 18 & $36.0 \%$ \\
\hline Laparotomy & 10 & $20.0 \%$ \\
\hline
\end{tabular}

Table 7 Distribution of study subjects as per associated complications

\begin{tabular}{|l|c|c|}
\hline $\begin{array}{l}\text { Complications } \\
\text { Pneumonia } \\
\text { consolidation }\end{array}$ & N & \% \\
\hline Pyothorax & 2 & $10.0 \%$ \\
\hline Septicaemia & 4 & $4.0 \%$ \\
\hline ARF & 1 & $2.0 \%$ \\
\hline MODS & 1 & $2.0 \%$ \\
\hline
\end{tabular}

Pneumonia developed in $10 \%$ cases while pyothorax and septicaemia was seen in $4 \%$ and $8 \%$ cases respectively.

Table 8 Association of type of trauma and Injury Severity Score

\begin{tabular}{|c|c|c|c|}
\hline \multirow{2}{*}{$\begin{array}{l}\text { ISS } \\
\text { Score }\end{array}$} & \multicolumn{2}{|c|}{ Type of Trauma } & \multirow[b]{2}{*}{ Total } \\
\hline & $\begin{array}{c}\text { Chest } \\
\text { Trauma }\end{array}$ & Poly-trauma & \\
\hline \multirow{2}{*}{$<15$} & 31 & 13 & 44 \\
\hline & $70.5 \%$ & $29.5 \%$ & $100.0 \%$ \\
\hline \multirow{2}{*}{$\begin{array}{l}>/= \\
15\end{array}$} & 1 & 5 & 6 \\
\hline & $16.7 \%$ & $83.3 \%$ & $100.0 \%$ \\
\hline \multirow{2}{*}{ Total } & 32 & 18 & 50 \\
\hline & $64.0 \%$ & $36.0 \%$ & $100.0 \%$ \\
\hline \multicolumn{4}{|c|}{ p- value $<0.01$} \\
\hline
\end{tabular}

Increased injury severity score was associated with poly-trauma patients $(\mathrm{p}<0.01)$.

\section{Discussion}

The American Academy of Science describes trauma as the "neglected disease of modern society". Chest injury can be broadly classified into Blunt chest injury and Penetrating chest injury. Blunt chest injury has been found to be more common than Penetrating chest injury.

In present study, we aimed to observe the clinical profile of cases with blunt trauma chest in reference to mode of injury, hospital stay, diagnosis, severity of injury, treatment offered, morbidity and mortality. Consecutive type of nonprobability sampling was used for the selection of study subjects during study duration. A total of 50 consecutive cases fulfilling the eligibility criteria were taken for study after informed consent.

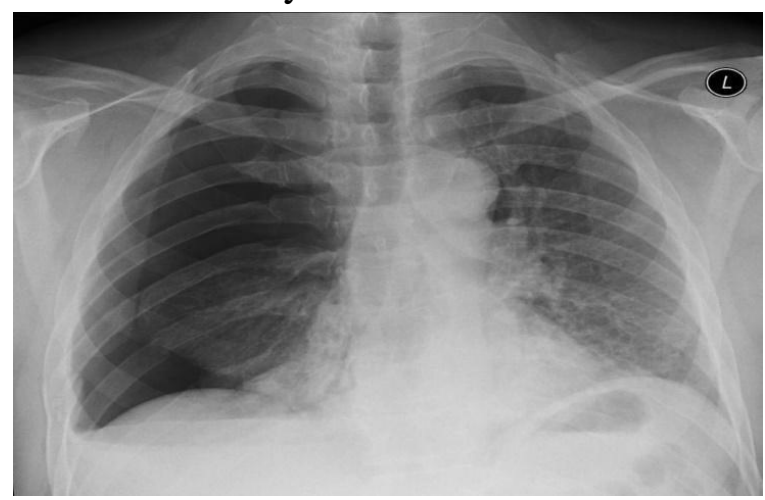

Image 1: Right sided Pneumothorax with Rib Fracture

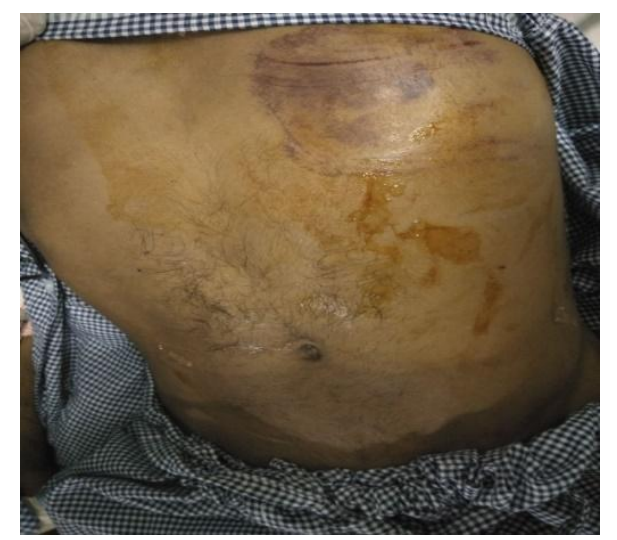

Image 2: A Patient of Blunt Trauma Chest 


\section{JMSCR Vol||07||Issue||11||Page 438-448||November}

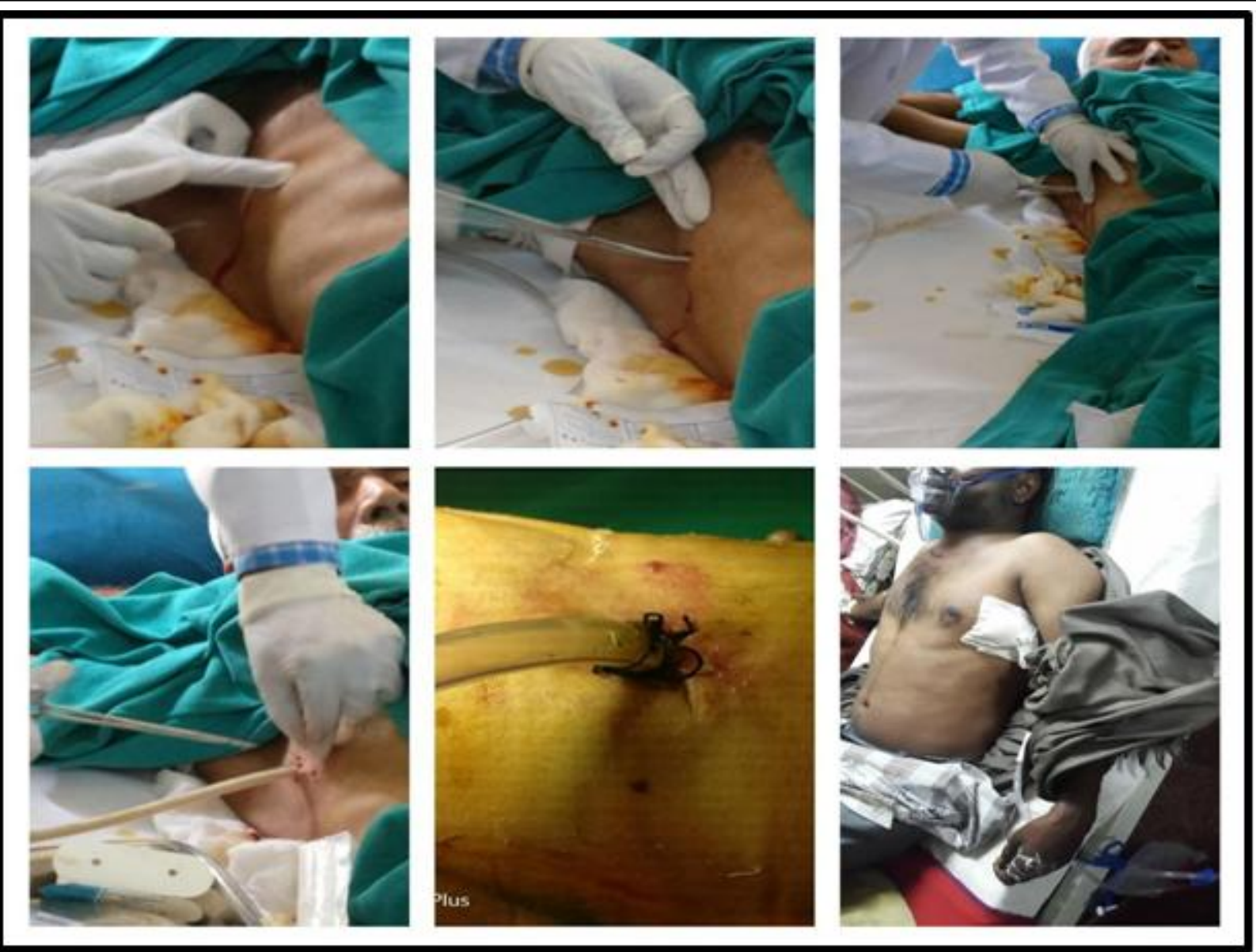

\section{Demography}

Trauma is usually considered as the main cause of mortality and morbidity in individuals between 1 to 44 years. Chest injuries are common reasons for emergency medical care. Most of the injuries are found among young adult males between the ages of 20 and 40 years i.e. the very productive period of life. In present study too, mean age of the subjects with Blunt Trauma Chest was 33.32 years with almost two third of cases belonging to 18-40 years of age $(64 \%)$. Male predominance was seen among study cases with $74 \%$ males to $26 \%$ females.

Demirhan $\mathrm{R}$ et al in their study of 501 cases of chest trauma, observed mean age as 32.2 years with $87.5 \%$ male and $12.5 \%$ females. Mean age in the study by Sirmali M et al. on 1417 cases of thoracic trauma was 43 years with 331 males to 217 females. Basoglu A et al. studied 521 patients of chest trauma with 399 males, and 122 females, with average age of 42 years. A similar study by Segers P et al. showed male: female ratio of 2.9:1 with average age of admission of 41.1 years. In a study by Sanjay Datey et al, 216 patient of chest trauma showed most cases from age group 21 to 30 years $(31.95 \%, 69$ of 216), with 174 males and 42 females. Saaiq M et al. studied 143 patient with chest trauma, 119(83\%) males and 24 (17\%) females with most common age group of 21 to 50 yrs. Esme $\mathrm{H}$ et al. studied 141 patients with 102 $(72.3 \%)$ males and 39 (27.7\%) females and mean age of 40 years. Kumar BA et al. conducted a cross sectional study on 200 patients with various forms of chest injuries. Males were commonly affected than female with 4.5:1 ratio, with mean age as 44.78 years. Kasbe PA et al. conducted a prospective observational study involving chest injury patients. A total of 150 chest injury patients were studied out of 864 patients of chest injury during the said period. Males outnumbered females by a ratio of 5:1. Their ages ranged from 10 to 80 years $($ mean $=37.27$ years $)$. Okonta $\mathrm{AE}$ et al. conducted a prospective study for a 4-year period at two tertiary hospitals in Nigeria. One- 
hundred and twenty-six (52.3\%) of 241 patients had blunt chest injuries (BCI), the average age was 40.4 years with a range of $0.8-79$ years. There were $104(82.5 \%)$ male with a ratio of 4.7:1.

\section{Mode of Injury}

Mode of injury was road traffic accident in 54\% cases while it was fall in $34 \%$ cases. Decelerated injury was observed in $76 \%$ cases while polytrauma was seen in $36 \%$ cases.

In the study by Demirhan R et al., RTA (72\%) was most common causative factor and polytrauma was seen in $37.5 \%$ of cases. Most common aetiology observed by Sirmali M et al. was RTA (330 cases) fall from height (122 cases), assault (54 cases) and industrial accidents (42 cases). In the study by Datey $\mathrm{S}$ et al., RTA was most common etiological factor (114, 57.4\%) followed by fall (20.8\%), assault (14.4\%), industrial accident (4.2\%) and animal attack (3.2\%). RTA was also the most common mode of injury in the studies by Basoglu et al. (62\%), Segers $\mathrm{P}$ et al. (72.2\%), Saaig $\mathrm{M}$ et al. (72\%), Kumar A et al. (78\%), Kasbe PA et al. (60\%), Shah JV et al. (76\%) Okonta AE et al. (74.6\%) and Alassal $\mathrm{M}$ et al. (66\%).

The results observed by other authors regarding incidence of polytrauma are as follows: Basoglu et al. (33\%), Esme H et al. (66\%).

\section{Clinical Presentation}

Most common presenting symptom was chest pain $(92 \%)$ followed by dyspnoea ( $82 \%)$, abdominal pain (24\%), nausea/vomiting (22\%) and hemoptysis (12\%). On general examination, abrasions, contusions and hematoma was seen in $70 \%, 54 \%$ and $26 \%$ cases respectively. Paradoxical chest movements and CCT was seen in $22 \%$ and $90 \%$ cases. In the study by Datey S et al, most common signs and symptoms comprised of pain and tenderness of chest wall (93.5\%) and respiratory distress in $83.8 \%$. Chest pain and respiratory distress were the commonest presentation observed in various other studies.
Esme $\mathrm{H}$ et al. in their study observed hypotension in $11.3 \%$ cases of chest trauma.

\section{Type of Injury}

Rib fractures were seen in 58\% cases while white opacification (s/o lung contusion) and scapulaclavicular fracture was seen in $18 \%$ and $22 \%$ cases respectively. Hemothorax, pneumothorax and Pneumo-hemothorax was seen in 52\%, 26\% and $12 \%$ cases respectively. As per injury severity score, low to medium severity injury was observed in $66 \%$ and $22 \%$ cases respectively. Severe injury was seen in $12 \%$ cases.

In a study by Sirmali M et al. on 1417 cases of thoracic trauma showed $38.7 \%$ had rib fracture. In a study by Sirmali $\mathrm{M}$ et al $38.7 \%$ cases had rib fracture followed by pneumothorax (37.2\%), hemothorax (26.8\%), haemopneumothorax (15.3\%), pulmonary contusion (17.2\%), flail chest $(5.8 \%)$ and surgical emphysema (2.2\%). Basoglu et al. in a similar study observed following injuries: Multiple rib fracture was present in 56\%, single rib fracture in $24 \%$ and flail chest in $8.4 \%$. Extra thoracic injuries was in $33.2 \%$ with the involvement of extremities at $41 \%$ and skull at $40 \%$. Common injuries observed in the study by Segers et al.were: rib fracture $(n=133)$, pulmonary contusion $(n=110)$, pneumothorax $(n=78)$ and hemothorax $(n=65)$. Datey $S$ et al. observed $82.4 \%$ cases of Blunt trauma chest with pneumothorax in $44.4 \%$, haemopneumothorax in $18 \%$ and contusion of lung in $17.6 \%$. Musculoskeletal injury was present in 58, head injury in 52 with abdominal and pelvic trauma in 19 patients. In the study by Saaig M et al. [109], rib fracture $(74 \%)$ was the most common chest injury. Ziegler DW et al. studied 7147 patients. Out of which 711 patients had rib fractures, $274(32 \%)$ had hemothorax or pneumothorax, $187(26 \%)$ had a lung contusion. Commonest injury observed by Kumar et al. were rib Fracture (78\%) followed by hemothorax (60\%) and Pneumothorax (44\%). In the study by Kasbe et al, rib fracture was the commonest type of chest injury followed by pneumothorax, $88 \%$ and $62 \%$ 
respectively. In the study by Shah JV et al, of the 100 studied patients, $64 \%$ had rib fractures, $17 \%$ had flail chest, $12 \%$ had pneumothorax, $24 \%$ had hemothorax, and 5\% had haemopneumothorax and $24 \%$ had extrathoracic injury. Common injuries observed in the study by Sah $\mathrm{S}$ et al. were pneumothorax followed by isolated multiple rib fracture, hemothorax, isolated single rib fracture haemopneumothorax, flail chest, subcutaneous emphysema, lung contusion, open pneumothorax and tension pneumothorax.

\section{Abdominal Injuries}

Injury to intra-abdominal organs was seen in $22 \%$ cases with liver being the most common organ involved $(10 \%)$ followed by spleen $-8 \%$, renal $2 \%$ and pancreas $-2 \%$.

In the study by Kumar et al, commonest associated solid abdominal organ injury is Liver (16\%) followed by Spleen (8\%). Associated injuries in the study by Okonta $\mathrm{AE}$ et al. were extremities 25 (19.8\%), cranio-spinal injuries $17(13.5 \%)$ and blunt abdominal injuries 13 $(10.3 \%)$. Liver is the most common affected intraabdominal organ in the studies by Esme $\mathrm{H}$ et al., Ziegler DW et al., Kumar A et al., Kasbe PA et al. $(11.97 \%)$ and Mohta M et al.

\section{Management}

Conservative management was sufficient in $36 \%$ cases while remaining cases required surgical intervention. Tube thoracotomy was required in $62 \%$ while mechanical ventilation was seen in $36 \%$ cases. Laparotomy was required in $20 \%$ cases. In the study by Demirhan $\mathrm{R}$ et al, management offered in 501 cases of chest trauma were Intercostal Tube Drainage in 332 (58\%), conservative in $185(32.5 \%)$, thoracotomy in $41(7.1 \%)$ and mechanical ventilation in 14 (2.4\%). In the study by Segers et al.most of cases were managed with observation and/or Intercostal Tube Drainage $(52.4 \%)$ and/or mechanical ventilation $(61.0 \%)$. A total of $10.2 \%$ patient required thoracotomy $(n=19)$. Main indications of thoracotomy were pulmonary laceration $(n=5)$, aortic rupture $(n=3)$ and diaphragmatic rupture $(n=3)$. In the study by Datey $S$ et al., 25\% cases needed only conservative treatment while 162 (75\%) needed surgical intervention with 159 patients requiring Intercostal Tube Drainage. In the study by Saaig $M$ et al, Intercostal Tube Drainage was done in $65(45 \%)$ patient and mechanical ventilation was given in $17(11.88 \%)$ patients. In the study by Esme $\mathrm{H}$ et al., symptomatic management was done in 76 (53.9\%), Intercostal Tube Drainage in 59(41.8\%) and thoracotomy in 11(7.8\%) patient. In the study by Kumar $\mathrm{A}$ et al, overall $76 \%$ patients required tube thoracostomy and $24 \%$ patients were managed conservatively.

\section{Complications \& Outcome}

Pneumonia developed in $10 \%$ cases while pyothorax and septicemia was seen in $4 \%$ and $8 \%$ cases respectively.

Common complications observed in the study by Segers et al. were pneumonia (38\%) and Acute Respiratory Distress Syndrome (7.0\%). Pneumonia as the commonest complication is also observed by Esme $\mathrm{H}$ et al, Kumar A et al. [120], Kasbe PA et al. (11.97\%) and Mohta $\mathrm{M}$ et al. $(9 \%)$.

Mortality rates observed in the studies by various authors is as follows: Demirhan R et al. (6.8\%), Sirmali M et al. (5.7\%), Basoglu et al. (7.1\%).

\section{Conclusion}

Blunt chest trauma is common among the middle age group and male sex. Increased outdoor activities and vehicular accidents are responsible for increased blunt chest trauma. The commonest injury was rib fracture followed by hemothorax and pneumothorax. Often a combination of these injuries were present. The most common associated injury was clavicle fracture while most common abdominal solid organ injury was that of liver. About two third cases required tube thoracotomy while $36 \%$ of cases were managed conservatively. Pneumonia was the most common complication encountered followed by septicemia 
and pyothorax. The overall mortality rate in this series was $4 \%$. The determinant of severe injury was polytrauma which leads to increased hospital/ ICU stay.

\section{References}

1. Murray, C.J. and A.D. Lopez, Alternative projections of mortality and disability by cause 1990-2020: Global Burden of Disease Study. Lancet, 1997. 349(9064): p. 1498-504.

2. World Health Organization. 2nd Global Status Report on Road Safety. 2011. Available from: http://www.who.int/entity/violence./global status report/flyeren.pd.

3. Carr BG, Caplan JM, Pryor JP, Branas CC. A meta-analysis of prehospital care times for trauma. Prehosp Emerg Care. 2006;10:198-206.

4. Wisner D, Trauma to chest. Sabiston and spencer B Saunders publication; 1995:6:456.

5. Miller DL, Mansour KA, Blunt traumatic chest injuries. Thoracic Surgery clinics. 2007; 17:57-61.

6. Locicero J, Mantox KL. Epidemiology of chest trauma. Surg Clin North Am 1989;69:5-16.

7. Sanjay Datey, Anurag Tayagi, Neelam Charles, Ashwin Lazarus, Mohan Gadodia, Mohit Gupta. "Study of Clinical Profile and Outcome of 216 Victims of Chest Trauma in Tertiary Care Centre of Central India." Journal of Evolution of Medical and Dental Sciences 2015; 4(93): 43-47.

8. Murray CJ, Lopez AD. Alternative projections of mortality and disability by cause 1990-2020: Global Burden of Disease Study. Lancet 1997; 349(9064): 1498-504.

9. Sanjay Datey, Anurag Tayagi, Neelam Charles, Ashwin Lazarus, Mohan Gadodia, Mohit Gupta, "Study of Clinical Profile and Outcome of 216 Victims of Chest Trauma in Tertiary Care Centre of Central India." Journal of Evolution of Medical and Dental Sciences 2015; Vol.4, Issue 93, November 19; Page: 15843-15847, DOI: 10.14260/jemds/2015/2297.

10. Saaiq M, Shah SA, "Thoracic trauma: presentation and management outcome." J Coll Physicians Surg Pak. 2008 Apr;18(4):2303.doi:04.2008/JCPSP.230233

11. Esme H, Solak O, Yurumez Y, Yavuz Y, "The factors affecting the morbidity and mortality in chest trauma", Ulus Travma Acil Cerrahi Derg. 2006 Oct;12(4):305-10

12. Arthurs ZM, Starnes BW, Sohn VY, Singh N, Martin MJ, Andersen CA. Functional and survival outcomes in traumatic blunt thoracic aortic injuries: an analysis of the National Trauma Databank. Journal of vascular surgery. 2009 Apr 1;49(4):98894.

13. West JG, Trunkey DD, Lim RC. Systems of trauma care: a study in two countries. Arch Surg 1979; 114: 455-60.

14. Standring S, editor. Gray's anatomy ebook: the anatomical basis of clinical practice. Elsevier Health Sciences; 2015.

15. Mary C Mancini. Blunt Chest Trauma. Medscape. Available at https://emedicine.medscape.com/article/42 8723-overview\#a3

16. Liman ST, Kuzucu A, Tastepe AI, et al. Chest injury due to blunt trauma. Eur J Cardiothorac Surg 2003; 23:374.

17. Rodriguez RM, Hendey GW, Marek G, et al. A pilot study to derive clinical variables for selective chest radiography in blunt trauma patients. Ann Emerg Med 2006; 47:415.

18. Fitzharris M, Franklyn M, Frampton R, et al. Thoracic aortic injury in motor vehicle crashes: the effect of impact direction, side of body struck, and seat belt use. J Trauma 2004; 57:582. 
19. McGwin G Jr, Reiff DA, Moran SG, Rue LW 3rd. Incidence and characteristics of motor vehicle collision-related blunt thoracic aortic injury according to age. $\mathrm{J}$ Trauma 2002; 52:859.

20. Nirula R, Talmor D, Brasel K. Predicting significant torso trauma. J Trauma 2005; 59:132.

21. Newman RJ, Jones IS. A prospective study of 413 consecutive car occupants with chest injuries. J Trauma 1984; 24:129.

22. Gaillard M, Hervé C, Mandin L, Raynaud P. Mortality prognostic factors in chest injury. J Trauma 1990; 30:93.

23. Fitzgerald M, Spencer J, Johnson F, et al. Definitive management of acute cardiac tamponade secondary to blunt trauma. Emerg Med Australas 2005; 17:494.

24. Fulda G, Brathwaite CE, Rodriguez A, et al. Blunt traumatic rupture of the heart and pericardium: a ten-year experience (19791989). J Trauma 1991; 31:167.

25. Ball CG, Kirkpatrick AW, Laupland KB, et al. Incidence, risk factors, and outcomes for occult pneumothoraces in victims of major trauma. J Trauma 2005; 59:917.

26. O'Connor JV, Kufera JA, Kerns TJ, et al. Crash and occupant predictors of pulmonary contusion. J Trauma 2009; 66:1091.

27. Eric Legome. Initial evaluation and management of blunt thoracic trauma in adults. Available at https://www.uptodate.com/contents/initialevaluation-and-management-of-bluntthoracic-trauma-in-adults\#H2

28. Kohn MA, Hammel JM, Bretz SW, Stangby A. Trauma team activation criteria as predictors of patient disposition from the emergency department. Acad Emerg Med 2004; 11:1.

29. Aho JM, Thiels CA, El Khatib MM, et al. Needle thoracostomy: Clinical effectiveness is improved using a longer angiocatheter. J Trauma Acute Care Surg 2016; 80:272.

30. Powell DW, Moore EE, Cothren CC, et al. Is emergency department resuscitative thoracotomy futile care for the critically injured patient requiring prehospital cardiopulmonary resuscitation? J Am Coll Surg 2004; 199:211.

31. Slessor D, Hunter S. To be blunt: are we wasting our time? Emergency department thoracotomy following blunt trauma: a systematic review and meta-analysis. Ann Emerg Med 2015; 65:297.

32. Rodriguez RM, Hendey GW, Mower W, et al. Derivation of a decision instrument for selective chest radiography in blunt trauma. J Trauma 2011; 71:549.

33. Millo NZ, Plewes C, Rowe BH, Low G. Appropriateness of $\mathrm{CT}$ of the chest, abdomen, and pelvis in motorized blunt force trauma patients without signs of significant injury. AJR Am J Roentgenol 2011; 197:1393.

34. Ho ML, Gutierrez FR. Chest radiography in thoracic polytrauma. AJR Am J Roentgenol 2009; 192:599.

35. Marnocha KE, Maglinte DD, Woods J, et al. Blunt chest trauma and suspected aortic rupture: reliability of chest radiograph findings. Ann Emerg Med 1985; 14:644.

36. Kram HB, Appel PL, Wohlmuth DA, Shoemaker WC. Diagnosis of traumatic thoracic aortic rupture: a 10-year retrospective analysis. Ann Thorac Surg 1989; 47:282.

37. Ekeh AP, Peterson W, Woods RJ, et al. Is chest $\mathrm{X}$-ray an adequate screening tool for the diagnosis of blunt thoracic aortic injury? J Trauma 2008; 65:1088.

38. Woodring JH. The normal mediastinum in blunt traumatic rupture of the thoracic aorta and brachiocephalic arteries. J Emerg Med 1990; 8:467.

39. Holmes JF, Ngyuen H, Jacoby RC, et al. Do all patients with left costal margin 
injuries require radiographic evaluation for intraabdominal injury? Ann Emerg Med 2005; 46:232.

40. Thompson BM, Finger W, Tonsfeldt D, et al. Rib radiographs for trauma: useful or wasteful? Ann Emerg Med 1986; 15:261.

41. Bansidhar BJ, Lagares-Garcia JA, Miller SL. Clinical rib fractures: are follow-up chest X-rays a waste of resources? Am Surg 2002; 68:449.

42. Expert Panel on Thoracic Imaging, Henry TS, Kirsch J, et al. ACR Appropriateness Criteria® rib fractures. J Thorac Imaging 2014; 29:364.

43. Rodriguez RM, Anglin D, Langdorf MI, et al. NEXUS chest: validation of a decision instrument for selective chest imaging in blunt trauma. JAMA Surg 2013; 148:940.

44. Omert L, Yeaney WW, Protetch J. Efficacy of thoracic computerized tomography in blunt chest trauma. Am Surg 2001; 67:660.

45. Shanmuganathan K, Mirvis SE. Imaging diagnosis of nonaortic thoracic injury. Radiol Clin North Am 1999; 37:533.

46. Brink M, Deunk J, Dekker HM, et al. Added value of routine chest MDCT after blunt trauma: evaluation of additional findings and impact on patient management. AJR Am J Roentgenol 2008; 190:1591.

47. Dissanaike S, Shalhub S, Jurkovich GJ. The evaluation of pneumomediastinum in blunt trauma patients. J Trauma 2008; 65:1340.

48. Hauser CJ, Visvikis G, Hinrichs C, et al. Prospective validation of computed tomographic screening of the thoracolumbar spine in trauma. $\mathrm{J}$ Trauma 2003; 55:228.
49. Plurad D, Green D, Demetriades D, Rhee P. The increasing use of chest computed tomography for trauma: is it being overutilized? J Trauma 2007; 62:631.

50. Kaiser ML, Whealon MD, Barrios C Jr, et al. Risk factors for traumatic injury findings on thoracic computed tomography among patients with blunt trauma having a normal chest radiograph. Arch Surg 2011; 146:459. 